\title{
Anthropological methods in curriculum instruction for learners in informal education for Abagusii of south western Kenya
}

\author{
Gilbert Nyakundi Okebiro
}

\begin{abstract}
Abagusii used methods known as anthropological for transformative education. Anthropological methods refer to indigenous ways for impacting knowledge and skills to children in the society. The methods differed in content and technique, but transformative education was moral, progressive, gradual and practical. The problem learners are ignoring anthropological methods because are indigenous and suppress transformative education for instance in acquiring university education, cannot adjust in the society. The objective is to examine the best approach to integrate, anthropological methods in curriculum development in educational system. The research employed survey method and data collected through questionnaire technique. Results indicates Abagusii have discarded anthropological methods for transformative education. The research paper concludes anthropological methods were transformative, effective and efficient in education since content was retained for long period by the learners. It recommends curriculum developers to incorporate them in the teaching-learning process in schools.
\end{abstract}

Keywords: Anthropological methods, Curriculum development, Transformative education

\section{Introduction}

The success of any education system depends not only on the nature of its aims, but also on its content (Sifuna \& Otiende 2009, p.151), therefore, the curriculum of the informal education among the Abagusii grew out of the immediate environment, real and imaginary, through the use of anthropological methods, which lead to transformative education. In this sense, Farrant (2009, p. 19) has defined informal education, as there is no attempt at structuring it and was transformative from one skill to another. Much of the learning goes on is almost unconscious, as with those things the child learns from his/her family, friends, experience and environment (Farrant 2009, p. 19).This is applicable in the modern educational system but the teachers and learners forget and do not apply them because the anthropological methods are transformative in nature which are not applied in curriculum instruction in modern educational systems.

Full listing of authors and contacts can be found at the end of this article.
Methods used in curriculum development instruction in Gusiland were varied and diversified in age sets or groups, which were practical and demonstrative in the curriculum. In the contemporary society, curriculum is a syllabus followed in educational system. In Gusiiland, education was imparted to the young beginning from birth until the end of life (death).In the modern society there are two types of basic education such as formal and informal. The former refers to education which is systematically planned in schools, colleges and universities. The latter is hidden learning that students undergo consciously or unconsciously within a school setting, for example assimilation desirable habits like punctuality, cleanliness, fairness, courtesy and so on which are portrayed by the staff and students in educational institutions globally (Farrant 2009, p. 19). This research refers to the latter where students were instructed informally using formal methods among the Abagusii. The curriculum instruction in Gusiiland was/ is done by dominated mountains (Ebitunwa), valleys, plains, rivers, grasslands and forests which were used asvenues for instruction (Bogonko 1994, p. 2). In the 
modern schools, children should be introduced and made aware of natural features in the neighborhood such as rivers, hills, dams, mountains, lakes and water falls (Ochieng 2015, p. 25). This features are seen and are within their experiences and children should learner about their uses for transformative education in Kenya. Therefore, according to Bogonko (1994, p. 2), some specialty was needed in making musical instruments-drums,flutes, harps, horns, and trumpets-from the animal remains, reeds and other grasses. These were some of the areas where formal instruction and training were undertaken (Bogonko 1994, p. 2). Studies of transfer training, however, indicated that student was much more likely to apply his learning when he recognized the similarity between the situations encountered in life and situations in which the learning took place (Tyler 2000, p. 18). In this aspect, the student was more likely to perceive the similarity between the life situations when two conditions were met: (1) the life situations and the learning situations were obviously alike in many respects, and (2) the students given practice in seeking illustrations in his life outside of school for the application of the things learned in school (Tyler 2000, p. 18).

Abagusii developed different systems of education to transmit their particular knowledge and skills to the learners, which they used as methods known as anthropological. Anthropological methods refer to the indigenous ways or devices for impacting knowledge and skills to the children in the society. The methods differed in content and technique, but the African indigenous education was moral, progressive, gradual and practical. The learners were taught how to cope with environment, how to farm, hunt or fish and prepare food or build a house and how to run a home. The methods were part of the culture among the Abagusii and learners were taught orally by their parents and community members.

The anthropological methods for curriculum instruction among the Abagusii, were classified into: Formal and informal. The informal methods included. First, learning to play-children engaged in many activities and the play activities were described as initiatory, imaginative and symbolic. Children also enjoyed imitating their parents or other grownups through play. A popular form of play was wrestling (E'nyameni) through the age mates and fostered physical strength. Other play activities includedswinging (Oborundarundi), chasing one another aimlessly, striding and dancing aimlessly. The second method was use of oral literature which included myths-which were tales effectively, described or accounted for natural phenomenon. Elderly people used to explain to the young children things they did not understand. Also legends were applied as methods of instruction. Legends were tales fabricated to account for real events that took place time immemorial. The Abagusii children also were instructed through folk-tales. Folk tales were used to teaching ethics and some of these had an exciting ending or sorrowful or frightening ending. Children also learned through dance and folksongs because a style of dance and folk song signified a type of rites, ceremonies, feasts and festival were performed through accompanying of melodious music and dancing. Ceremonies, feasts and festivals were important sources of teaching. Proverbs were used widely in ordinary conversation. Uses of proverbs (Emebayeno) were seen as a sign of wit/intelligence by the user, proverbs were a condensed wisdom of the Abagusii ancestors.

The third anthropological method of instruction among the Abagusii was traditional learning by use of deterrence or inculcating fear method. Children were taught morals and good behavior as they were born into the clan as a sign of transformative education taught in the stages of child growth and development. According to Sifuna et al, (2006, p. 64), verbal warnings were used and more often followed by punishment for the offenders. Children who committed offences were rebuked, smacked or assigned some piece of work, which expected to be completed before being allowed to eat. Serious offenses resulted into severe beating and leading to reformatory. Deception was another deterrent method especially used with the young.

The fourth method was involving children in productive work. (Ogosoma/Chisemi) Learning through medium of work enabled children acquires right type of masculinity and feminist roles. Children learnt by being useful, by doing and working hand-in-hand with adults-this prepared children to become capable future husbands and wives. Training of the children was done according to age and sex.such that the work that a child did usually increased in amount and complexity as s/he grew up. Also the physical ability of the child was taken into consideration; a child was not assigned a task beyond his/her physical fitness (Sifuna et al 2006, p. 64).

In the formal methods, it involved theoretical and practical inculcation of skills. Learning through apprenticeship was formal and direct method. Children were instructed and trained as craftsmen such as potters, blacksmiths and basket makers/weavers by teaching 
them formally. Formal instructions were also given in constant corrections and warning to children, in domestic work, in herding, in cultivation and tending to certain crops, in fishing and so on. According to Sifuna and Otiende (2009, p. 154) formal education took the form of succeeding stages of initiation from status. The most prominent of initiation practices was the form of circumcisition.Circumcision (Okwaroka) was normally accompanied with formal lessons (Sifuna \& Otiende 2009 , p. 154), which were done through the anthropological methods of instruction and were transformative in nature. The instructors used to test whether or not the initiate understood the lessons, by use of songs. The questions were asked in a form of riddles (Chimbachero) for the initiate to interpret their meaning. Such questions dealt with issues pertaining to the protection of homestead (Enka y'omugusii) against enemies committing adultery and many others (Sifuna \& Otiende 2009, p. 154).

\section{The statement of the problem}

The problem nowadays children are ignoring the anthropological methods of instruction because they are indigenous and cannot adjust in the society after acquiring formal in university education girls for example are not able to prepare food and depend on maids and boys cannot run a home, as they depend on services from servants.

\section{The objective of the study}

The objective is to examine the best approach in integrating the anthropological methods in curriculum development in educational system in Kenya.

\section{Hypotheses}

H1- There is no significant relationship between the anthropological methods to students in school for transformative education in Kenya.

$\mathrm{HO}$ - There is significant relationship between the anthropological methods to students in schools for transformative education in Kenya.

\section{Literature Review}

The term curriculum is derived from a Latin word "Curere" which implies a racecourse or track followed by racing horses. As time went by, the racecourse came to be likened to course of study followed by learners in educational institutions. This thereafter, led to emergence of the term curriculum, which its initial meaning implies curriculum is a process or set of activities that has a beginning and an end. Curriculum simply is the syllabus, but in much more complex terms "curriculum" is much more than the syllabus or course outline. This means the anthropological methods were infused in the informal curriculum of education among the Abagusii leading transformative education. Kerr (1969) defines curriculum as "all the learning which is planned or guided by the school whether it is carried out in groups or individuals inside or outside the school." According to Mbithi (2009, p. 54), curriculum refers to what is taught at any given level of the school system. It refers to all the learning experiences that a learner goes through within a specified period in order to attain certain set objectives.

Curriculum development is understood to include a repeating process of planning based on national policies, production of instructional material, and implementation of the programme through the allocation of resources and evaluation (Peiris 1976, p. 1).In this aspect, a comprehensive meaning od curriculum development include all of the following aspects of the curriculum: (a) The content or subject matter of the instructional programme, in this case of the Abagusii for example circumcision was done openly for transformative education in the society. (b)Instructional materials for instance teaching/learning aids or resources such as horns,skins, and so on were used. (c) Instructional methods or strategies to achieve stated objectives, in this sense Abagusii used the anthropological methods for transformative education.(d) The methods of evaluating the degree to which the intended objectives have been achieved.

Children were highly valued in African communities, because they played a very important role in the family and the community (Kabiru \& Njenga 2009, p. 14).According to Kabiru and Njenga (2009, p. 19), ancient Romans began to educate children as soon as they could speak, probably they used the anthropological methods which are discussed in this paper. The Tabula rasa view emerged during the 17 th century from teaching of John Locke. To him, children were born as "Clean slates" ready to be moulded through experiences and he advised parents to spend a lot of time with their children and guide them through instructions, examples and rewards such as praise and approval. This was also done through the anthropological methods applied in classical Gusiiland, but in the contemporary modern society they are no longer applicable. Education grew out of the immediate environment, real and imaginary. From the physical environment, children had to learn 
about the weather, type of landscapes, animals and plants. Above knowledge the children had to be acquainted with the problems and possibilities of the environment by being equipped with skills of overcoming and exploiting them-by use of axe, hoe, the spear and other tools of the past in the Stone Age period.

Children were taught how to cope with the environment, how to farm, how to hunt, how to fish or prepare food or build a house and how to run or manage a home. Individual was to live and serve other people in accordance with accepted manners, laws, avoidance of taboos and a rigorous code of morality. Every person in the homestead and its environment, parents and old relatives were responsible for the training in economic responsibilities. Learning by imitation played a big role, for young boys and old men, were building, herding and hunting, for girls and women, sweeping, carrying wood from the forest, carrying water from the river/fetching water and cooking. Indigenous education inculcated a religious attitude of life because religion was concerned morality and rules of conduct such as courtesy, generosity and honesty.

\section{Methodology}

The research employed survey method and data collected through questionnaire technique. The study used a survey research design on the primary and secondary schools in Kisii county. Mugenda \& Mugenda (2003) noted that surveys are the excellent vehicles for the measurement of characteristics of large population. The design was appropriate because it helped the researcher to obtain information that describes phenomenon by asking individual students about their perceptions, attitudes, behavior or values related to the anthropological methods of curriculum instruction among the Abagusii.

\section{Data collection procedure}

A structured questionnaire was used as the main instrument of data collection from respondents/students. A total of 400 questions were distributed in ten schools in Kisii through stratified random sampling and 380 were returned to the researcher having an aggregate of $95 \%$ of the total questionnaires distributed. The data collected were analyzed, summarized and interpreted using simple percentage and chi-square method to measure inconsistency between the observed and expected frequencies and to prove the significance in the stated hypothesis. The responses from the questionnaires were measured using Likert scale five- point scale namely: Strongly agree (5 points), disagree (4 points), Undecided ( 3 points), disagree ( 2 points) and strongly disagree (1 point).This is used to register and know to what extent of agreement or disagreement with a particular statement of and attitude, belief or judgments in concept of anthropological methods in curriculum instruction for transformative education.

\section{Results}

The following summary describes the data collected from the field survey (2018) applied in the test subject classrooms. $(n=380)$.

Table 1 indicates that 220 or 57.8 percent of the respondents were males and 160 or 42.2 percent were females. This shows that most of the respondents were males.

Table 1. Gender of respondents

\begin{tabular}{ccc}
\hline Gender & Frequency & Percentages \\
\hline Male & 220 & 57.8 \\
Female & 160 & 42.2 \\
Total & 380 & 100 \\
\hline
\end{tabular}

Table 2 indicates that 180 or 47.4 percent were between the ages of $10-13$ while 200 or 52.6 percent of the respondents were between the ages of 14-17 years. This means that the majority of the respondents were over 13 years of age and in secondary schools.

Table 2. Age of respondents

\begin{tabular}{ccc}
\hline Age & Frequency & Percentage \\
\hline $10-13$ & 180 & 47.4 \\
$14-17$ & 200 & 52.6 \\
18 and above & - & - \\
\hline
\end{tabular}

Table 3 shows that 150 or 39.5 percent of the respondents were in primary schools while 239 or 60.5 were in the secondary level of education. This revealed that most of the respondents were in secondary schools.

Table 3. Student level in education system

\begin{tabular}{ccc}
\hline Level & Frequency & Percentage \\
\hline Primary & 150 & 39.5 \\
Secondary & 230 & 60.5 \\
\hline
\end{tabular}


Table 4. The anthropological methods applied for corrections or warning

\begin{tabular}{ccc}
\hline Scale & Frequency & Percentage \\
\hline Strongly agree & 280 & 73.7 \\
Agree & 74 & 19.5 \\
Undecided & 6 & 1.6 \\
Disagree & 12 & 3.2 \\
Strongly disagree & 8 & 2.1 \\
\hline
\end{tabular}

Table 4 shows that 280 or 73.7 percent of the respondents strongly agree that the anthropological methods are applied for corrections or warning students/children, while 74 or 19.5 percent of the respondents are the similar views and agree; 6 or 1.6 percent were undecided;12 or 3.2 percent disagree and 9 or 2.1 strongly disagree. Obviously, the majority of the respondents believed that anthropological methods in curriculum development have an impact on the student's transformative education.

Table 5. Learners acquire skills through apprenticeship

\begin{tabular}{ccc}
\hline Scale & Frequency & Percentage \\
\hline Strongly agree & 280 & 73.7 \\
Agree & 100 & 26.3 \\
Undecided & - & - \\
Disagree & - & - \\
Strongly disagree & - & - \\
\hline
\end{tabular}

Table 5 indicates learners attached to teacher to acquire skills through apprenticeship, thus 280 or 73.7 percent of the respondents strongly agree while 100 or 26.3 percent of the respondents agree.

Table 6. Anthropological methods focused on socioeconomic and environmental locale

\begin{tabular}{ccc}
\hline Scale & Frequency & Percentage \\
\hline Strongly agree & 280 & 73.7 \\
Agree & 100 & 26.3 \\
Undecided & - & - \\
Disagree & - & - \\
Strongly disagree & - & - \\
\hline
\end{tabular}

In Table 6 Anthropological methods were focused on socio-economic and environmental locale, 280 or 73.7 percent of the respondents strongly agree and 100 or 26.3 percent of the respondents agree. This depicts that the locale was the major area used for transformative education when applying anthropological methods in curriculum development in informal education.
Table 7. Anthropological methods applied in natural and human resources for transformation

\begin{tabular}{ccc}
\hline Scale & Frequency & Percentage \\
\hline Strongly Agree & 230 & 60.53 \\
Agree & 144 & 37.89 \\
Undecided & 6 & 1.58 \\
Disagree & - & - \\
Strongly disagree & - & - \\
\hline
\end{tabular}

Table 7 shows the Anthropological methods applied in natural and human resources for transformation and this aspect 230 or 60.53 percent strongly agree, 144 or 37.89 percent agree and 6 or 1.58 undecided. This indicates that the environment was the field of study where natural and human resources were available.

Table 8 illustrates Knowledge transfer and knowledge applicable in real life, therefore 280 or 73.7 percent respondents strongly agree; 74 or 19.5 percent respondents agree; 6 or 1.6 respondents undecided;12 or 3.2 percent respondents agree and 8 or 2.1 percent of the respondents strongly disagree.

Table 8. Knowledge transfer and knowledge applicable in real life

\begin{tabular}{ccc}
\hline Scale & Frequency & Percentage \\
\hline Strongly Agree & 280 & 73.7 \\
Agree & 74 & 19.5 \\
Undecided & 6 & 1.6 \\
Disagree & 12 & 3.2 \\
Strongly disagree & 8 & 2.1 \\
\hline
\end{tabular}

\section{Test of the hypothesis}

Chi-square $\left(\mathrm{X}^{2}\right)$ tool was used, with an alternative hypothesis stating that there is no significant relationship between the anthropological methods to students in school for transformative education in Kenya. The test suggests that the alternative hypothesis should be accepted $\left(\mathrm{p}<0.001, \mathrm{X}^{2}=411,342, d f=16\right)$.

\section{Discussion}

The study has an enduring transformative change in education system, because the anthropological methods were used in every child and existed for the purpose of strengthening the community and should be used in the modern school for transformative education. The formal instructions were given in the constant corrections and warning the children, in some aspects of domestic work such as herding animals and tending 
certain crops, which a transformative agriculture projects done in the formal education.

The study challenged the status quo of the traditional ways of teaching and learning where anthropological methods are not applicable. The economic role of the children featured prominently in their training and parents saw their new born babies in economic terms. All this descriptions of early African life make this a close link between education and economics, because within the homesteads and its environments, the parents and older relatives were responsible for the training in economic responsibilities (Kabiru \& Njenga 2009, p. 14).

The paper elevates the youth and adult voice and democratic practices in schools and in the society, as Sifuna and Otiende (2009, p. 151) supports the idea that "a child was expected to learn largely by seeing (observation) and imitating". In this sense a child was given a formal teaching usually after had made a mistake and when the outcome of the work was found unsatisfactory.

The paper serves to create a more equitable and sustainable future because, technical skills were learned on the apprenticeship principle. The learners were attached to the teachers in order to acquire skills. Even the teacher-student ratios were small and in some cases it was one teacher to one learner. This should be applicable in the modern schools for transformative education in Kenya.

The paper focuses on the natural and human resources that are available in the locale or area as the resource such as mountains (Ebitunwa), valleys, plains, rivers, grasslands and forests which were used as venues for instruction for the student engagement, which are not applicable nowadays because students are confined in classrooms and go out on breakfast breaks and lunch breaks

The paper elicits knowledge transfer and knowledge applicability in real-life contexts since traditional education (informal education) used well-tried anthropological methods for teaching such as games, riddles, legends and acting - all related to culture and traditions of the Abagusii ethnic group. Also Sifuna and Otiende (2009, p. 151), argue that the informal methods of instruction included involving children in productive work. The learning trough medium of work enabled children to acquire the right type of their masculine and feminine roles in the real-life.

The paper encourage student-driven, collaborative project-based learning as the anthropological methods had its structure of responsibility for who taught what was well defined, and the need for different teachers as the children matured were recognized. The children were taught how to cope the environment, how to farm, how to hunt and so on, which was part of focusing on social, environmental and economic problems in the locale or area.

methods were used in communalism, collective activity, cooperation and social responsibility were valued and emphasized in traditional education among the Abagusii. In this sense, the individuals were to live and serve other people in accordance with the accepted manners, customs, laws, avoidance of taboos and a rigorous code of morality.

The paper nurture youth and parent/adult with partnership strategies for effective service learning as the family was recognized as the cornerstone of traditional life and a lot of learning took place at home under the guidance of parents and the extended family members.

The paper promotes authentic indigenous knowledge systems and indigenous ways of knowing and doing as the anthropological methods were remarkably comprehensive and holistic, because its main aim was to integrate the child fully into the life of the community.

Results indicate Abagusii have discarded the use of some of anthropological methods in instructing children in the family systems. The commonwealth secretariat of 1993 gives the meaning of the curriculum as a combination of the following perspectives and dimensions. The first perspective is official curriculum: this is a planned curriculum laid out in official documents such as syllabuses, catalogues, and prospectus and so on. Official curriculum consists of numerous courses or subject and course or subject combinations.

The second perspective is actual or real curriculum. This is the received curriculum or reality of the student experiences for example to say what is actually taught in the educational institutions. The actual curriculum can also be viewed in terms of what individual student study as shown in the transcripts or certificates.

The third perspective is hidden curriculum. It is a powerful perspective of the curriculum in institutions of learning. It respects the unplanned experiences and un intended outcomes in the area which students go through and develop as a result of the process of specialization in the institution for example music, athletics, football, drama and so on.

The fourth perspective is ideal curriculum. This is a 
curriculum that a society aspires to have for it to realize its cherished dreams and ambitions. This forms the basis and directions and provides the guiding framework for the design of the curriculum. The ideal curriculum states the standard by the society's contexts or what the society would like to have.

There are three dimensions on focus as follows: one formal dimension - in or out activities that are part of the planned experiences for example syllabus contents, laboratory experiments, field work, agricultural projects, home science projects, computer science projects and so on.Two, non-formal dimension - planned and guided activities which may be outside the formal syllabuses. It also refers to as co-curricular activities or sometimes in the past it used to be called extra-curricular (not worthwhile planned) examples including games, music, drama and so on. The third dimension is informal. It refers to socialization process through which students acquire certain habits as a result of interacting to the total environmental and the culture of educational institution for the manner of self-dressing, style of speech, styles of movements, self-image, cleanliness, leadership styles and so on. The process of socialization affects students attitudes, growth and behavior, some of which may not be desired.

\section{Conclusion}

It is concluded curriculum is viewed as an explicitly and implicitly intentional set of interactions or activities designed to facilitate learning and development and impose meaning on experience. In this sense, the anthropological methods have the explicit intention usually are expressed in written documents denoting (expressing) courses of study for instance syllabuses, course outlines the anthropological included for transformative education. The implicit intentions for anthropological methods are found in hidden curriculum which refer to unplanned learning which takes place as a result of interaction between students and fellow students, between students and the staff of the school and between students and subject matter and finally between students and school facilities.

The research paper concludes anthropological methods of instruction were effective and efficient as they are both informal and formal and were practical in nature and the objectives; content is retained for long period in the lifetime of the learners. The anthropological methods were effective in transmissions and preservation of culture, skills, knowledge of the family, clan among the Abagusii from one generation to another.
The anthropological methods were adapting children into their physical and human environment where they were, in Gusiiland. In this sense, the anthropological methods instilled the accepted standards, norms, beliefs and traditions governing the correct behaviors among the children and adults in the society. This created unity and cooperation in the Omogusii society, the methods emphasized on collective responsibility, for instance children could be disciplined by any member not only parents particularly. Through the anthropological methods, the children acquired practical skills and knowledge which would be useful to the individual child and the omogusii society. Intellectual skills such as observation, problem and decision making are quite relevant in the transformative education in the world today.

\section{Recommendation}

Basing on the conclusion, the paper recommends curriculum developers in the education system, Kenya Institute of Curriculum Development (KICD) to incorporate anthropological methods in the curriculum for the teaching-learning process in schools. It recommends for transformative education to be effective and efficient, the integrated approach to curriculum development is required in primary, secondary, tertiary and university levels, therefore, the stakeholders should take action of implementation.

It is recommended, in the modern schools, learners should be introduced and made aware of natural features in the neighborhood such as rivers, hills, dams, mountains, lakes and water falls, through the use of anthropological methods, because the features are seen and are within their experiences and learners should learner about their uses for transformative education in Kenya. 


\section{References}

Bogonko, S. N. (1994). A History of modern education in Kenya (1875-1991). Nairobi:Evans Brothers (Kenya) Ltd.

Farrant, J. S. (2009). Principles and practice of education. Malaysia: Longman.

Kabiru, M. \& Njenga, A. (2009). Foundations of early childhood development and education and curriculum development. Nairobi: Focus Publishers Ltd.

Kerr, J. F. (1969). Changing the curriculum. London: University of London Press.

Mbiti, D. M. (2009). Foundations of school administration, Oxford University Press: Nairobi. Mugenda, O. M. and Mugenda, A. G.(2003). Research methods: Quantitative and qualitative approaches. Nairobi: ACTS Press.

Ochieng, E. (2015). Social environmental activities, Nairobi: Longhorn Publishers.

Peiris, K. (1976). Integrated approach to curriculum development in primary education in Sri Lanka. Singapore: The UNESCO Press.

Sifuna, D. N., Chege, F. N., \& Oanda, I. O. (2006). Themes in the study of the foundations of education. Jomo Kenyatta Foundation: Nairobi.

Sifuna, D. N., \& Otiende, J. E. (2009). An introductory history of education. Nairobi: University of Nairobi Press.

Sifuna, D. N., Chege, F. N., \& Oanda, I. O. (2006). Themes in the study of the foundations of education. Nairobi: The Jomo Kenyatta Foundation.

Tyler, R. W. (2000). Basic principles of curriculum development and instruction. Chicago: The University of Chicago Press.

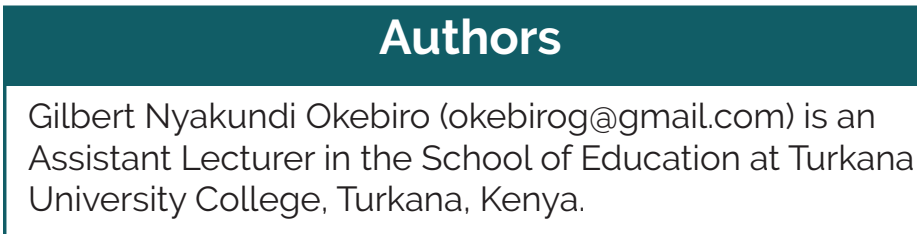




\section{Appendix 1 \\ Questionnaire}

\section{Anthropological methods in curriculum instruction for learners in informal education for Abagusii of south western Kenya}

Kindly fill in the appropriate or correct answer to questions using:

Strongly agree(SA)=5points; Agree(A)=4 Points; Undecided(U) 3 Points; Agree(A)=2 points; Strongly disagree(1 point)

1. Gender:

\begin{tabular}{|l|l|}
\hline Male & \\
\hline Female & \\
\hline
\end{tabular}

2. Age of the respondents

\begin{tabular}{|l|l|}
\hline $10-13$ & \\
\hline $14-17$ & \\
\hline 18 and above & \\
\hline
\end{tabular}

3. Level of education/status

\begin{tabular}{|l|l|}
\hline Primary & \\
\hline Secondary & \\
\hline
\end{tabular}

4 .The relevance of anthropological methods in curriculum development for transformative education

\begin{tabular}{|l|l|l|l|l|l|}
\hline Factor & $\begin{array}{c}\text { Strongly } \\
\text { agree }\end{array}$ & Agree & Undecided & Disagree & $\begin{array}{l}\text { Strongly } \\
\text { disagree }\end{array}$ \\
\hline $\begin{array}{l}\text { The anthropological methods applied } \\
\text { for corrections warning students/ } \\
\text { children }\end{array}$ & & & & & \\
\hline $\begin{array}{l}\text { Learners attached to teacher to } \\
\text { acquire skills through apprenticeship }\end{array}$ & & & & & \\
\hline $\begin{array}{l}\text { Anthropological methods applied } \\
\text { in natural and human resources for } \\
\text { transformative }\end{array}$ & & & & & \\
\hline $\begin{array}{l}\text { Knowledge transfer and knowledge } \\
\text { applicable in real life }\end{array}$ & & & & & \\
\hline $\begin{array}{l}\text { Anthropological methods focused on } \\
\text { socio-economic and environmental } \\
\text { locale }\end{array}$ & & & & & \\
\hline
\end{tabular}

Thank for your cooperation for filling the questionnare. God bless you 